\title{
Increased Susceptibility to Helicobacter pylori Infection in Pregnancy
}

\author{
S. Lanciers, ${ }^{1,2}$ B. Despinasse, ${ }^{1}$ D.I. Mehta, ${ }^{3}$ and U. Blecker ${ }^{2,3}$ \\ ${ }^{1}$ Division of Pediatric Gastroenterology, Louisiana State University Medical Center, \\ New Orleans, LA \\ ${ }^{2}$ Division of Pediatric Gastroenterology, Academic Children's Hospital, Free University of \\ Brussels, Belgium \\ ${ }^{3}$ Division of Pediatric Gastroenterology, Alfred I. duPont Hospital for Children, Wilmington, DE
}

\begin{abstract}
Objective: Helicobacter pylori plays a major role in abdominal symptoms and gastroduodenal pathology, including gastric cancer. Pregnancy has been associated with changes in both humoral and cell-mediated immunity. These changes include alterations in the various classes of antibodies during different gestational periods. It has been previously suggested that these alterations may expose pregnant women to an increased risk of infection with this microorganism.

Methods: To further investigate this hypothesis, we assayed sera from 229 asymptomatic pregnant women for the presence of $\boldsymbol{H}$.-pylori-specific immunoglobulin $\mathrm{G}$ ( $\mathrm{IgG}$ ) and immunoglobulin $\mathrm{M}$ (IgM) antibodies by means of a commercially available serum ELISA test (Malakit ${ }^{\mathrm{TM}}$, Biolab, Belgium). Both tests were previously validated in large series of $H$.-pylori-positive and -negative subjects. While the presence of $H$.-pylori-specific IgG antibodies is only a marker for a "chronic" infection with this bacterium and therefore no indicator of the time of acquisition of the infection, specific IgM antibodies are a more specific marker for a recently acquired infection with $\mathrm{H}$. pylori. Results were compared with those previously obtained in asymptomatic, healthy, nonpregnant individuals.

Results: One hundred twenty of 229 women $(52.4 \%)$ and 55/118 nonpregnant subjects (46.6\%) were seropositive for $H$.-pylori-specific IgG antibodies $(P>0.3)$. Out of these 120 IgG-antibodypositive women, $36(30 \%)$ were positive for $H$.-pylori-specific IgM antibodies, as were 25/109 $(22.9 \%)$ in the IgG-antibody-negative group $(P>0.3)$. Overall, 61/229 $(26.6 \%)$ of the pregnant women had recently been infected with $H$. pylori, compared with $11 \%$ of the healthy, nonpregnant population $(P>0.01)$.

Conclusions: Our observations confirm the possibility of an increased susceptibility to $H$. pylori infection in pregnancy. Additional studies are necessary to further understand the immune response to H. pylori in pregnancy. Infect. Dis. Obstet. Gynecol. 7:195-198, 1999.
\end{abstract}

() 1999 Wiley-Liss, Inc.

$H$ elicobacter pylori has been found to be the major cause for gastroduodenal pathology, both in adults ${ }^{1,2}$ and in children, ${ }^{3,4}$ a finding that resulted in a new understanding of and approach to chronic active gastritis, duodenal ulcers, and, to a lesser degree, gastric ulcers.

The exact route of transmission of $H$. pylori is still not well understood. We know that the human

Correspondence to: Uwe Blecker, MD, Department of Gastroenterology, Alfred I. duPont Hospital for Children, 1600 Rockland Road, P.O. Box 269, Wilmington, DE 19899. E-mail: ublecker@nemours.org 
body is the only natural reservoir for $H$. pylori and that, therefore, person-to-person transmission is the most likely method of transmission. ${ }^{5}$ A number of factors, such as crowding index, ${ }^{6}$ low socioeconomic status, ${ }^{7}$ an infected family member, ${ }^{8}$ and ethnicity, ${ }^{9}$ have all been linked to a higher incidence of $H$. pylori infection.

Recently it has been suggested that this bacterium might play an important role as a cofactor in the development of gastric adenocarcinoma ${ }^{10,11}$ and lymphoma. ${ }^{12,13} \mathrm{H}$. pylori infection increases with advancing age. ${ }^{14}$ We previously demonstrated that $H$. pylori infection is also present in symptomfree subjects, both in childre ${ }^{15}$ and adults. ${ }^{16}$

Pregnancy has been associated with changes in both humoral and cell-mediated immunity. Although not yet completely understood, these changes include alterations in the various classes of antibodies during different gestational periods, which may lead to an increased susceptibility to certain infections. ${ }^{17}$ Our study was designed to explore whether pregnant women are at an increased risk for acquiring $H$. pylori infection due to immunological changes that occur during pregnancy.

To minimize potential differences in risk factors between the investigated groups, all subjects were pooled from the same population and matched for age and socioeconomic background.

\section{METHODS}

\section{Patients}

We investigated 229 healthy pregnant women (ages 20 to 40 years) and 118 healthy nonpregnant women (ages 18 to 40 years) for the presence of H.-pylori-specific antibodies. The subjects were Caucasians of middle to upper socioeconomic class and background and were matched for age. Both groups were asymptomatic with regard to gastrointestinal symptoms and were not taking any antibiotics, $\mathrm{H}_{2}$-blockers, or proton pump inhibitors for at least 6 weeks. Pregnant women were tested at routine prenatal visits during their second trimester. The control group was comprised of women who were tested during routine prenatal screening. As mentioned above, the exact route of transmission and risk factors for $H$. pylori infection are still not quite understood. To minimize the impact of any such risk factors, all investigated subjects were drawn from the same population.

\section{Serology}

The sera were tested using the Malakit ${ }^{\mathrm{TM}}$ Helicobacter pylori series (Biolab S.A., Limal, Belgium), a solid-phase (microwells) two-step indirect ELISA method based on the sandwich principle for the detection of specific immunoglobulin M (IgM) or immunoglobulin $\mathrm{G}$ ( $\mathrm{IgG}$ ) antibodies to $H$. pylori in human sera. This assay uses fractionated and purified antigens for $H$. pylori. During the first step, samples and controls are diluted 1:200 and incubated in microwells at $37^{\circ} \mathrm{C}$ for 45 minutes to form an $H$. pylori antigen/anti-H.-pylori-antibody complex. The unbound components are washed off. In the subsequent incubation (at $37^{\circ} \mathrm{C}$ for $45 \mathrm{~min}$ utes), a rabbit anti-human-IgM peroxidase conjugate is added to react with the H. pylori antigen/ anti-H.-pylori-antibody complexes. Unreacted conjugate is washed off. After the addition of azinobenzthiazoline sulfonate (ABTS) and a last incubation step (at $37^{\circ} \mathrm{C}$ for 60 minutes), the enzymatic reaction is stopped with a fixator $(\mathrm{NaOH})$.

The intensity of the green coloration is measured at $405 \mathrm{~nm}$ and is directly proportional to the amount of anti- $H$. pylori antibodies in the sample. A positive control giving an absorbency higher than 1,000 is used to ensure that the entire test protocol is working properly.

A positive result for $H$.-pylori-specific IgM antibodies by this ELISA technique was defined as an IgG level two or more standard deviations above the mean of all negative IgG and IgM titers previously obtained by the company (company's unpublished data) and our group. ${ }^{18,19}$

\section{Statistics}

The Fisher exact test was used for statistical calculations.

\section{RESULTS}

One hundred twenty of 229 pregnant $(52.4 \%)$ and $55 / 118(46.6 \%)$ nonpregnant women were positive for $H$.-pylori-specific IgG antibodies $(P>0.3)$. Out of the $120 \mathrm{IgG}$-antibody-positive pregnant women, $36(30 \%)$ were positive for $H$.-pylori-specific IgM antibodies, as were $25 / 109(22.9 \%)$ in the IgGantibody-negative group $(P>0.3)$.

In the nonpregnant control group, $8 / 55(14.5 \%)$ IgG-positive and 5/63 (7.9\%) IgG-negative subjects were positive for $H$.-pylori-specific IgM antibodies.

Overall, $61 / 229(26.6 \%)$ of the pregnant women 
had recently been infected with $H$. pylori, as defined by positivity for specific IgM antibodies, compared with $13 / 118(11 \%)$ in the nonpregnant population $(P>0.01)$. This reflects a relative risk of 2.21 (95\% confidence interval, 2.02-2.40) of becoming infected with $H$. pylori during pregnancy $(P$ $>0.01)$.

\section{DISCUSSION}

Pregnancy is associated with a number of modifications and adaptations. Although it has been well established that immunoregulation and immunomodulation occur during pregnancy, it is important to fully understand the effects these changes have on a pregnant woman's susceptibility to infectious agents. In this study we sought to elucidate whether pregnant women are at an increased risk for acquiring $H$. pylori infection.

Prior studies have confirmed the prevalence of H. pylori seropositivity in asymptomatic children and adults. ${ }^{15,16} H$. pylori has been linked to chronic gastritis, peptic ulcer disease and, to a lesser extent, gastric adenocarcinoma and gastric lymphoproliferative disease, specifically low-grade B-cell lymphoma. ${ }^{1,10,12,20}$ In view of the important pathogenesis of $H$. pylori, it is important to investigate the maternal history of $H$. pylori infection in H.-pyloripositive pregnant women.

Recently, we investigated the role of passive immunity and the evolution of $H$. pylori infection in children born to mothers with active $H$. pylori infection from parturition to twelve months of age. We were able to demonstrate that these infants do not appear to have an increased risk of developing H. pylori infection during their first year of life. ${ }^{21}$

Looking at asymptomatic women in both the pregnant and control groups, the pregnant women in our study had a significantly higher relative risk of acquiring the disease. Therefore, this study confirms the possibility of an increased risk of acquiring $H$. pylori infection during pregnancy.

The presence of H.-pylori-specific IgG has not been shown to be protective. In addition, both groups had comparable prevalences for anti-H.pylori IgG antibodies. This excludes the possibility of $\mathrm{IgG}$ titers as a cause for the increased incidence of specific IgM antibodies in our pregnant population.

During pregnancy, physiologic alterations occur that increase the potential for gastrointestinal symptoms; in late pregnancy the rise in serum progesterone levels causes lower esophageal sphincter tone to decrease. ${ }^{17}$ Additionally, intragastric pressure increases and the intraesophageal pressure decreases while gastric $\mathrm{pH}$ and gastric acid output remain unchanged. ${ }^{17}$ But pregnancy may also convey a relative protective effect against the formation of peptic ulcer disease. With the above noted, there remains the possibility that the well-known increased incidence of gastrointestinal symptomatology during pregnancy ${ }^{22}$ is related to $H$. pylori disease. Recently it has been suggested that $H$. pylori infection may cause hyperemises gravidarum. $^{23}$

Follow-up studies are needed to delineate the pregnant women's complete immune response in the face of infection with $H$. pylori. As we better understand the pregnant host's immune response, it will aid in the prevention of future disease through possible prenatal screening exams and vaccination programs, as well as possible pharmacotherapy and immunotherapy alternatives.

Based on our findings of an increased incidence of $H$. pylori infection during pregnancy, further studies may be required to investigate the indication of screening for $H$. pylori in pregnant women.

\section{ACKNOWLEDGMENTS}

We would like to thank Yvan Vandenplas, MD, $\mathrm{PhD}$, for his guidance in the design of this study and his help in collecting the serum samples and patient information. We thank Biolab for providing us with the Helicobacter pylori ELISA kits.

\section{REFERENCES}

1. Warren JR, Marshall BJ. Unidentified curved bacilli on gastric epithelium in active chronic gastritis. Lancet 1983;i:1273-1275.

2. Johnston BJ, Reed PI, Ali MH. Prevalence of Campylobacter pylori in duodenal and gastric mucosa - relationship to inflammation. Scand J Gastroenterol 1988;23:69 75 .

3. Bujanover Y, Konikoff F, Baratz M. Nodular gastritis and Helicobacter pylori. J Pediatr Gastroenterol Nutr 1990;11:41-44.

4. Kilbridge PM, Dahms BB, Czinn SJ. Campylobacter pylori associated gastritis and peptic ulcer disease in children Am J Dis Child 1988;142:1149-1152.

5. Ma J, You WC, Gail MH, et al. Helicobacter pylori infection and mode of transmission in a population at high risk of stomach cancer. Int J Epidemiol 1998;27:570 573. 
6. Malaty HM, Paykov V, Bykova O, et al. Helicobacter pylori and socioeconomic factors in Russia. Helicobacter 1996;1:82-87.

7. Fiedorek SC, Malaty HM, Evans DL, et al. Factors influencing the epidemiology of Helicobacter pylori infection in children. Pediatrics 1991;88:578-582.

8. Blecker U, Lanciers S, Mehta DI, Vandenplas Y. Familial clustering of Helicobacter pylori infection. Clin Pediatr 1994;33:307-308.

9. Lanciers S, Mehta DI, Hauser B, Vandenplas Y, Blecker $\mathrm{U}$. The prevalence of Helicobacter pylori positivity in asymptomatic children of different ethnic background living in the same country. Ethnicity Health 1996;1: 169-173.

10. Parsonnet J, Friedman GD, Vandersteen DP, et al. Helicobacter pylori infection and the risk of gastric carcinoma. N Engl J Med 1991;325:1127-1131.

11. Parsonnet J, Friedman GD, Orentreich N, Vogelman H. Risk for gastric cancer in people with CagA positive or CagA negative Helicobacter pylori infection. Gut 1997;40: 297-301.

12. Blecker U, McKeithan TW, Hart J, Kirschner BS. Resolution of Helicobacter pylori-associated gastric lymphoproliferative disease in a child. Gastroenterology 1995; 109:973-977.

13. Wotherspoon AC, Doglioni C, Diss TC, et al. Regression of primary low-grade B-cell gastric lymphoma of mucosa-associated lymphoid tissue type after eradication of Helicobacter pylori. Lancet 1993;342:575-577.

14. Blecker U, Lanciers S, Hauser B, Vandenplas Y. The prevalence of Helicobacter pylori in a symptom-free population, aged 1 to 40 years. J Clin Epidemiol 1994; 47:1095-1098.

15. Blecker U, Hauser B, Lanciers S, et al. The prevalence of Helicobacter pylori positive serology in asymptomatic children. J Pediatr Gastroenterol Nutr 1993;16:252-256.

16. Blecker U, Lanciers S, Hauser B, Vandenplas Y. Helicobacter pylori positivity in Belgium. Acta Gastroenterol Belg 1995;58:31-34.

17. Landers DV, Bronson RA, Pavio CS, Stites DP. Reproductive Immunology. In Stites DP, Terr AI (eds): Basic Human Immunology. Norwalk, CT: Appleton \& Lange, 1991, p 200-215.

18. Blecker U, Lanciers S, Hauser B, de Pont S, Vandenplas $\mathrm{Y}$. The contribution of specific IgM antibodies to the diagnosis of Helicobacter pylori infection in children. Eur J Gastroenterol Hepatol 1995;7:979-983.

19. Blecker U, Lanciers S, Hauser B, Vandenplas Y. Diagnosis of Helicobacter pylori infection in adults and children by using Malakit Helicobacter pylori, a commercially available enzyme-linked immunosorbent assay. J Clin Microbiol 1993;31:1770-1773.

20. Blecker U. Helicobacter pylori-associated gastroduodenal disease in childhood. South Med J 1997;90:570-576.

21. Blecker U, Lanciers S, Keppens E, Vandenplas Y. Evolution of Helicobacter pylori positivity in children born from positive mothers. J Pediatr Gastroenterol Nutr 1994;19:87-90.

22. Borum ML. Gastrointestinal diseases in women. Med Clin North Am 1998;82:21-50.

23. Frigo P, Lang C, Reisenberger K, Kolbl H, Hirschl AM. Hyperemesis gravidarum associated with Helicobacter pylori seropositivity. Obstet Gynecol 1998;91:615-617. 


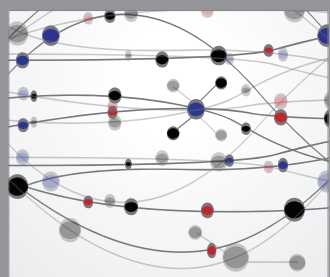

The Scientific World Journal
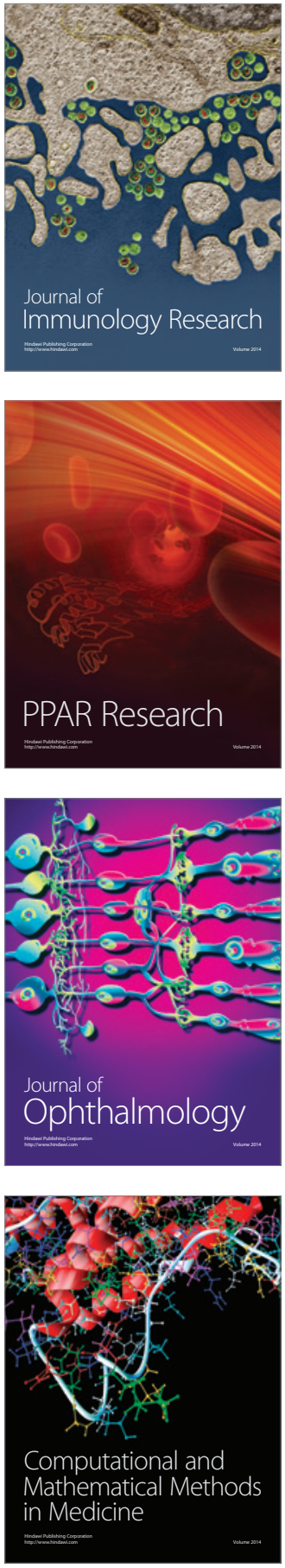

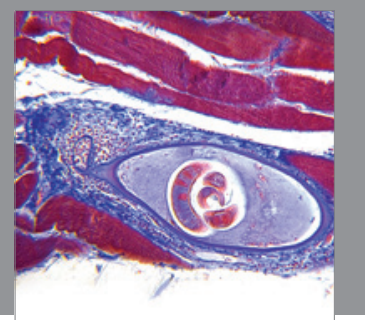

Gastroenterology

Research and Practice
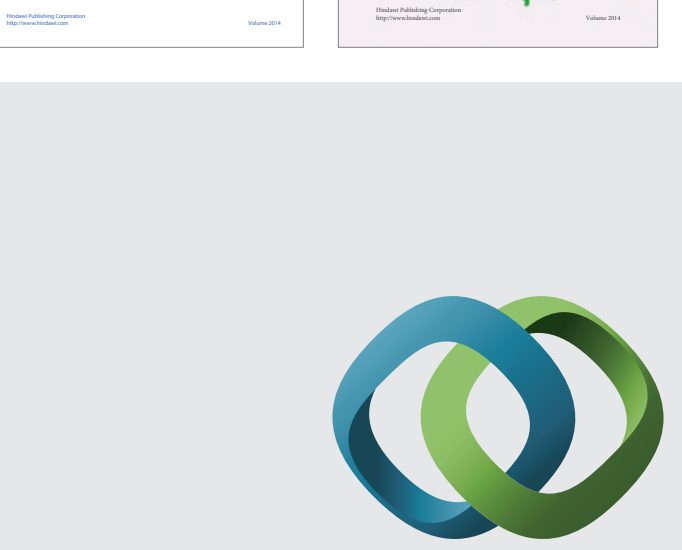

\section{Hindawi}

Submit your manuscripts at

http://www.hindawi.com
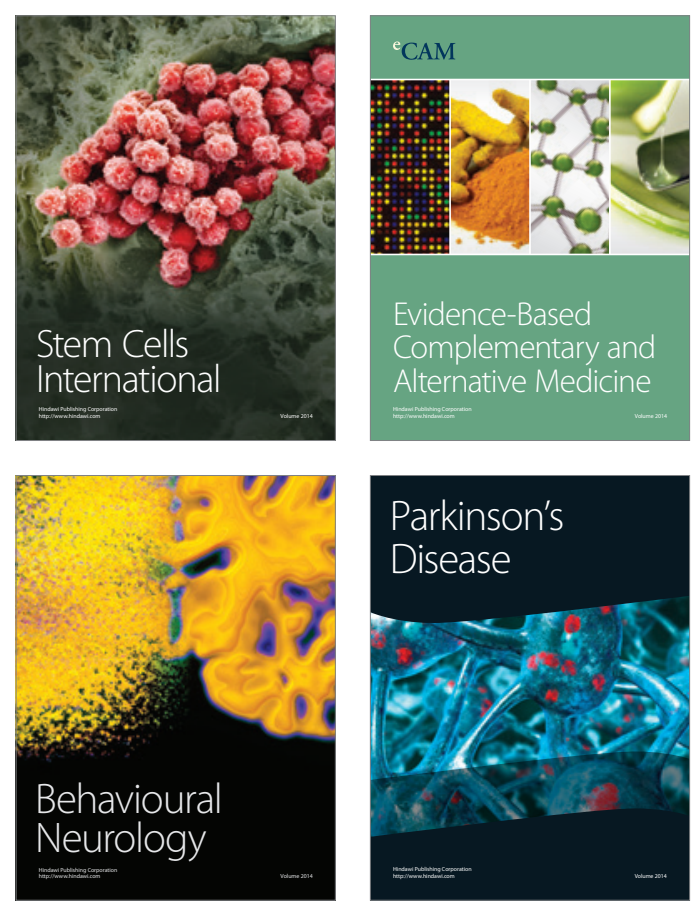

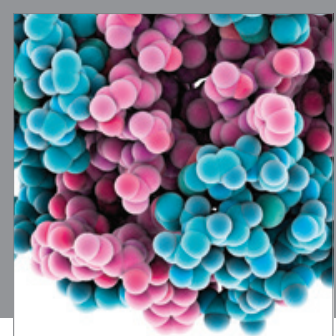

Journal of
Diabetes Research

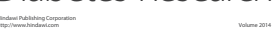

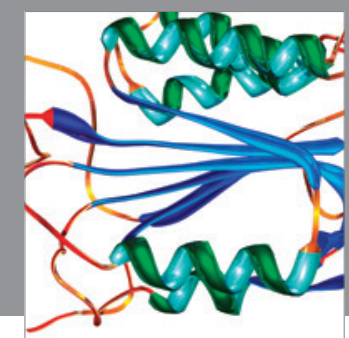

Disease Markers
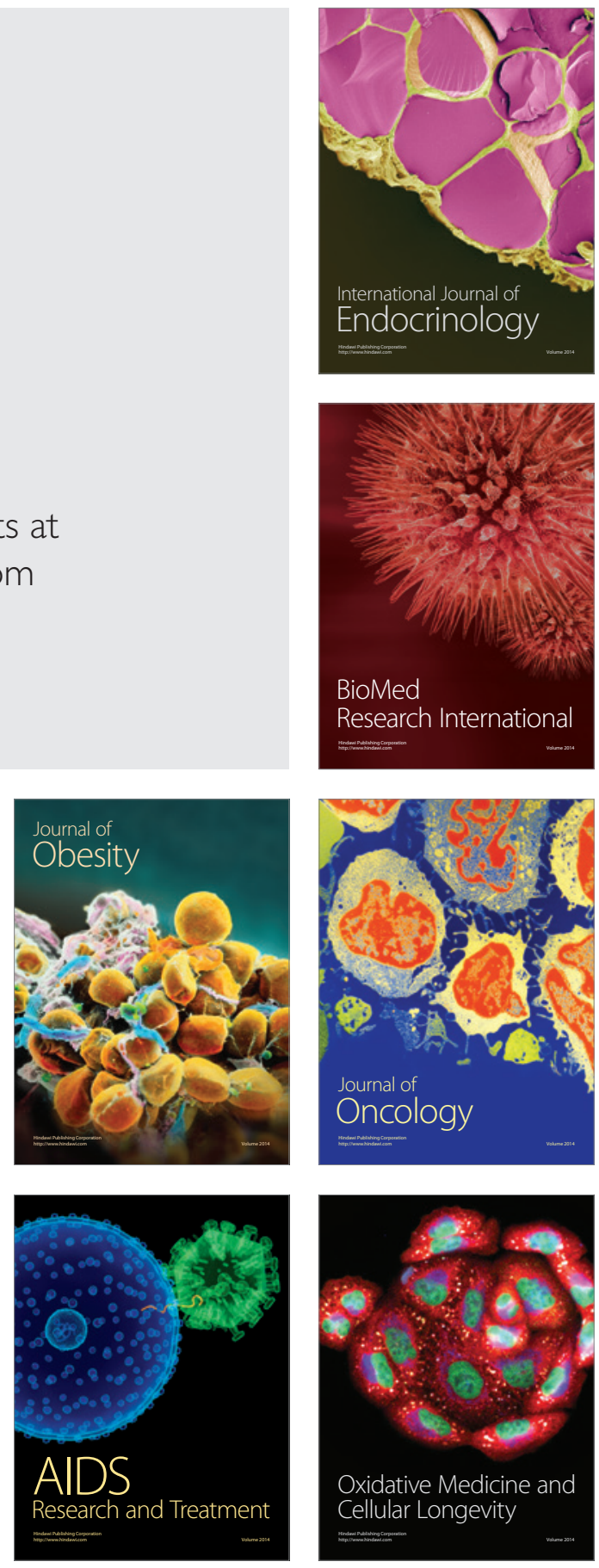